\section{(2) OPEN ACCESS}

\title{
Regional variation in cardiovascular magnetic resonance service delivery across the UK
}

\author{
Niall G Keenan (D) , 1,2 Gabriella Captur (D) , 3,4 Gerry P McCann, ${ }^{5,6}$ Colin Berry (D) , 7,8 \\ Saul G Myerson (D) , ${ }^{9}$ Timothy Fairbairn, ${ }^{10}$ Lucy Hudsmith, ${ }^{11}$ Declan P O'Regan (D) , \\ Mark Westwood, ${ }^{12}$ John P Greenwood (D) 13,14
}

For numbered affiliations see end of article.

\section{Correspondence to}

Dr Niall G Keenan, Cardiology, West Hertfordshire Hospitals NHS Trust, Watford WD18 OHB, UK; n.keenan@imperial.ac.uk

Received 17 November 2020 Revised 16 February 2021 Accepted 20 February 2021
Check for updates

(C) Author(s) (or their employer(s)) 2021. Re-use permitted under CC BY-NC. No commercial re-use. See rights and permissions. Published by BMJ.

\footnotetext{
To cite: Keenan NG, Captur G, McCann GP, et al. Heart Epub ahead of print: [please include Day Month Year]. doi:10.1136/ heartjnl-2020-318667
}

\begin{abstract}
Objectives To examine service provision in cardiovascular magnetic resonance (CMR) in the UK. Equitable access to diagnostic imaging is important in healthcare. CMR is widely available in the UK, but there may be regional variations.

Methods An electronic survey was sent by the British Society of CMR to the service leads of all CMR units in the UK in 2019 requesting data from 2017 and 2018. Responses were analysed by region and interpreted alongside population statistics.

Results The survey response rate was 100\% (82 units). 100386 clinical scans were performed in 2017 and 114967 in 2018 (15\% 1-year increase; 5-fold 10-year increase compared with 2008 data). In 2018, there were 1731 CMR scans/million population overall, with significant regional variation, for example, 4256 scans/million in London vs 396 scans/million in Wales. Median number of clinical scans per unit was 780, IQR 373-1951, range 98-10 000, with wide variation in mean waiting times (median 41 days, IQR 30-49, range 5-180); median 25 days in London vs 180 days in Northern Ireland). Twenty-five units (30\%) reported mean elective waiting times in excess of 6 weeks, and 8 $(10 \%) \geq 3$ months. There were 351 consultants reporting CMR, of whom 230 (66\%) were cardiologists and 121 (34\%) radiologists; $81 \%$ of units offered a CMR service for patients with pacemakers and defibrillators.

Conclusions This survey provides a unique, contemporary insight into national CMR delivery with $100 \%$ centre engagement. The 10 -year growth in CMR usage at fivefold has been remarkable but heterogeneous across the UK, with some regions still reporting low usage or long waiting times which may be of clinical concern.
\end{abstract}

\section{INTRODUCTION}

Cardiovascular magnetic resonance (CMR) is an advanced cross-sectional imaging technique and the reference standard for assessment of left ventricular (LV) and right ventricular (RV) volumes and function. ${ }^{1}$ It has a wide variety of clinical applications including coronary artery disease, cardiomyopathy, heart failure, aortopathy, valvular and congenital heart disease. ${ }^{2}$ In international guidelines, the American College of Cardiology Appropriate Use Criteria Task Force, with other allied bodies, have deemed CMR as appropriate in the assessment of complex congenital heart disease, ${ }^{3}$ stable ischaemic heart disease, ${ }^{4}$ heart failure, cardiomyopathy, pericardial disease, cardiac masses, aortic disease, cardiac sarcoidosis and cardiac amyloidosis, ${ }^{5}$ and in more challenging cases of regurgitant valvular heart disease. ${ }^{6}$ In the European Society of Cardiology guidelines on chronic coronary syndromes, non-invasive functional imaging including CMR stress perfusion has a class I indication in the initial diagnostic management of symptomatic patients with suspected and known coronary artery disease. ${ }^{7}$ In heart failure guidelines, it has a class IIa indication for the assessment of dilated cardiomyopathy and a class I indication in patients with poor echo windows and in patients with certain suspected aetiologies of heart failure such as myocarditis, sarcoidosis and amyloidosis. ${ }^{8}$

Despite several class I and class II recommendations in the guidelines, there are wide variations nationally and internationally in terms of access to CMR, with availability remaining a major barrier to more widespread use of this technology. The funding of CMR in the UK is complex with different models in England, Northern Ireland, Scotland and Wales. Scanners may be purchased by the National Health Service (NHS) or private hospitals, or by universities, or with charitable funds, and within the NHS running costs may be reimbursed either by local or national commissioners of heathcare.

The British Society of CMR (BSCMR; www. bscmr.org) has periodically surveyed CMR units in the UK. Two previous surveys have been published in 2011 (2008-2010 data) and 2014 (2013 data; abstract only). ${ }^{9} 10$ The current survey sought to examine CMR growth over a 10-year time horizon, and to assess regional variation and other characteristics of CMR units in the UK. A similar study has recently been performed looking at the provision of cardiac CT in the UK, ${ }^{11}$ as has a further study looking more generally at cardiac imaging provision. $^{12}$

\section{METHODS}

Board members of the BSCMR identified all CMR units in the UK. In the case of England they reviewed all 223 NHS Trusts/hospitals to assess for the presence or absence of a CMR unit. In cases of doubt, further inquiries were made on the hospital's website and by telephone with the cardiology and radiology departments. In Scotland, Ireland and Wales, where services are more centralised, direct approaches were made to CMR 
practitioners in the region to identify all hospitals with a CMR unit. For all CMR units the service lead was identified. During 2019, the CMR lead for each Trust was sent an electronic survey (www.sogosurvey.com) to capture key service delivery metrics, including clinical scan volumes for the previous 2 years (2017 and 2018), and separately research scan volumes for 2018. The complete list of questions is provided in box 1 . In cases of nonresponse, reminders were sent with follow-up emails and finally telephone calls. The population of each region within the UK was derived from publicly available data or from the Office for National Statistics. ${ }^{13} 14$ Statistics were performed in Microsoft Excel (Microsoft) and RStudio (RStudio, Boston, Massachusetts, USA). Continuous variables were assessed for normality via a histogram, and for skewed data variables are presented as median, IQR and range where illustrative. Data were analysed by region of the UK and compared with population statistics. Patient and public involvement was not deemed relevant to the design of the study, which was by its nature a survey.

\section{RESULTS}

\section{Services and scanners}

In 2019, there were $82 \mathrm{CMR}$ units in the UK, and we achieved a $100 \%$ response rate to the survey. Of these, 71 were in England, 1 in Northern Ireland, 6 in Scotland and 4 in Wales. In the 2014 survey there were 68 units, and in the 2011 survey (2008-2010 data) 60 units, representing a $37 \%$ increase in CMR centres in the last decade. Thirty-seven units were in secondary care (district hospitals) and 45 in tertiary care/regional/academic centres. For every million people in the population, there were 1.3 CMR units in England, 0.5 in Northern Ireland, 1.1 in Scotland and 1.3 in Wales.

The total number of MRI scanners used for CMR was 166 (median 2/centre, IQR 1-3, range 1-5). Of those who provided manufacturer information, 107 (72\%) were Siemens, 30 (20\%) Philips, $9(6 \%)$ General Electric and $2(1 \%)$ others. In terms of field strength, 123 (81\%) were 1.5 T, 27 (18\%) $3 \mathrm{~T}$ and 1 other. The median age of magnets was 4 years, IQR $1-8$, range new to 15 years old; 17 (14\%) magnets were 10 years old or older. The median age of CMR units was 10 years, IQR 6-14 years, range $1-35$ years.

In terms of scanner distribution, 139 were in England, 4 in Northern Ireland, 17 in Scotland and 6 in Wales. For every million people in the population, there were 2.5 CMR-enabled MRI scanners in England, 2.1 in Northern Ireland, 3.1 in Scotland and 1.9 in Wales. Within England this varied between 2.9 scanners/million in both London and Northeast and Yorkshire regions, and 1.3 scanners/million in the East of England region.

\section{Staffing}

We identified 351 consultant physicians reporting CMR, of whom 230 (66\%) were cardiologists and 121 (34\%) radiologists. The median number of reporting consultants per unit was 4, IQR 2-6, range 1-16. There were in addition 148 fellows, and 411 technologists involved in CMR services. Per million/ population the number of CMR consultants was 5.4 in England, 5.3 in Northern Ireland, 4.2 in Scotland and 4.5 in Wales.

\section{Volume}

The total number of clinical CMR scans performed in the UK was 100386 in 2017 and 114967 in 2018, a 15\% increase in 1 year. In addition, there were 10126 research scans performed in 2018. For comparison, in previous surveys the total annual number of scans in 2008 was 20 597, and in 2010 it was 38
Box 1 Questions in the British Society of Cardiovascular

Magnetic Resonance (BSCMR) 2019 survey

1. What is the name of your Trust?

2. What is the name of the CMR lead in your Trust?

3. What is the email of the CMR lead in your Trust?

4. Is your hospital district general/secondary care or academic/ tertiary care?

5. How many MRI scanners do you have that are used for CMR?

6. For each scanner please answer: manufacturer, age, field strength?

7. How is your clinical CMR service funded? (National Health Service England specialised commissioning/national tariff, Clinical Commissioning Group/local negotiation, other)?

8. Reporting

- Number of CMR cardiology consultants reporting?

- Number of CMR radiology consultants reporting?

- Number of CMR fellows in dept?

- Number of CMR techs in dept?

9. Clinical indication (\%)

- Heart failure

- Cardiomyopathy

- Function and viability

- Stress perfusion

- Acquired vascular disease

- Valvular heart disease

- Myocarditis

- Pericardial disease

- Paediatric and congenital heart disease

- Cardiac transplantation/others (eg. masses).

10. Service delivery

- What year did CMR start?

- How many clinical CMR scans performed in 2018?

- How many clinical CMR scans performed in 2017?

- How many half day CMR sessions per week total across all scanners?

- How many patients per half day session?

- Mean inpatient waiting time? (days)

- Mean outpatient waiting time? (days)

11. Do you have a programme for pacemaker/device patients?

12. If you have a programme for pacemaker/device patients, do you only scan conditional devices or also non-conditional devices?

13. Do you have general anaesthetic lists?

14. Do you have an interventional CMR programme?

15. Do you have access to T1 mapping?

16. Do you have a quality assurance programme in place?

17. Do you have a regular CMR meeting?

18. Do you have an audit programme?

19. Are you part of a hub-and-spoke model?

20. Training

- How many trainees are there in your department?

- Which level is training offered to? $(1 / 2 / 3)$

- How many level 3 accredited trainers are there in your department?

21. Is research performed in your department?

22. Is there external, peer-reviewed research grant funding contributing to research in your department (during past 12 months)?

23. How many research CMR scans in 2018 ? 
485 , although the response rate in these surveys did not achieve $100 \%$. This therefore represents an estimated fivefold growth in 10 years.

In 2018 , the median number of scans/centre was 780, IQR 373-1951, range 98-10 000. In 2017, these data were median 750, IQR 374-1600, range 100-7500 based on 80 centres, as two services started in 2018. For comparison, in 2008 the median number of scans was 240 .

By head of UK population in 2018, there were 1731 scans/ million people. Table 1 shows these data by region. The number of scans/million population were 1907 scans in England, 1302 in Northern Ireland, 827 in Scotland and 396 in Wales. In England, this varied between 4256 scans/million in the London region and 985 scans/million in the Southeast region (figure 1A).

A significant part of the growth has been in the numbers of scans performed in each centre as well as an increase in the number of centres. Data for annual scan volume by centre are shown in table 2 and figure 2A with data from 2013 for comparison. Three very high-volume centres performed $>5000$ scans/ year.

\section{Waiting times}

Centres reported their mean outpatient referral to diagnostic (RTD) scan time. The median RTD was 41 days, IQR 30-49 days, range 5-180 days. Twenty-five (30\%) centres had a mean RTD longer than 42 days (6 weeks), and $8(10 \%)$ had a mean RTD of 90 days or more. The median reported RTD was 40 days in England, 180 days in Northern Ireland, 55 days in Scotland and 50 days in Wales. By region in England, the median reported RTD ranged from 25 days in London to 44 days in the Southwest region (table 1 , figures $1 \mathrm{~B}$ and $2 \mathrm{~B}$ ). The median reported inpatient RTD was 3 days, IQR 2-4 days, range 0-7 days.

\section{Indications}

The mean percentage for each indication for CMR was heart failure $21 \%$, cardiomyopathy $27 \%$, function and viability $22 \%$, stress perfusion $24 \%$, acquired vascular disease $6 \%$, valvular heart disease $5 \%$, myocarditis/pericardial disease $10 \%$, paediatric/congenital heart disease $10 \%$, cardiac transplant $0.4 \%$, others, for example, cardiac masses $3 \%$. This adds up to $>100 \%$ likely indicating some overlap between indications. Of 70 centres answering a question about the performance of stress perfusion CMR, 58 (83\%) indicated that they had a stress perfusion service.

\section{Quality/Research/Training}

Of the 74 units answering questions on clinical governance, $66(89 \%)$ had a formal quality assurance (QA) programme, $63(85 \%)$ had a regular CMR clinical meeting and $58(78 \%)$ had a regular audit programme. Forty-four (59\%) of 74 units were active in research. Of these units, the median number of research scans was 100/year, IQR 30-377, range 2-1600. Fiftythree $(72 \%)$ of 74 units had cardiology/radiology trainees, mean number per unit 3.4, range 1-25. Thirty-seven (23\%) units were offering training up to level 3 and a further 15 (20\%) to level 2.

\section{Other aspects of CMR service}

Seventy-four units provided data on whether they had a service for patients with cardiac implanted electronic devices (pacemakers and defibrillators). Of these, $60(81 \%)$ provided this service; 20 (33\%) were scanning both MRI conditional and nonconditional devices, with 40 (67\%) scanning MRI conditional devices only. The 14 (19\%) units that did not have a service

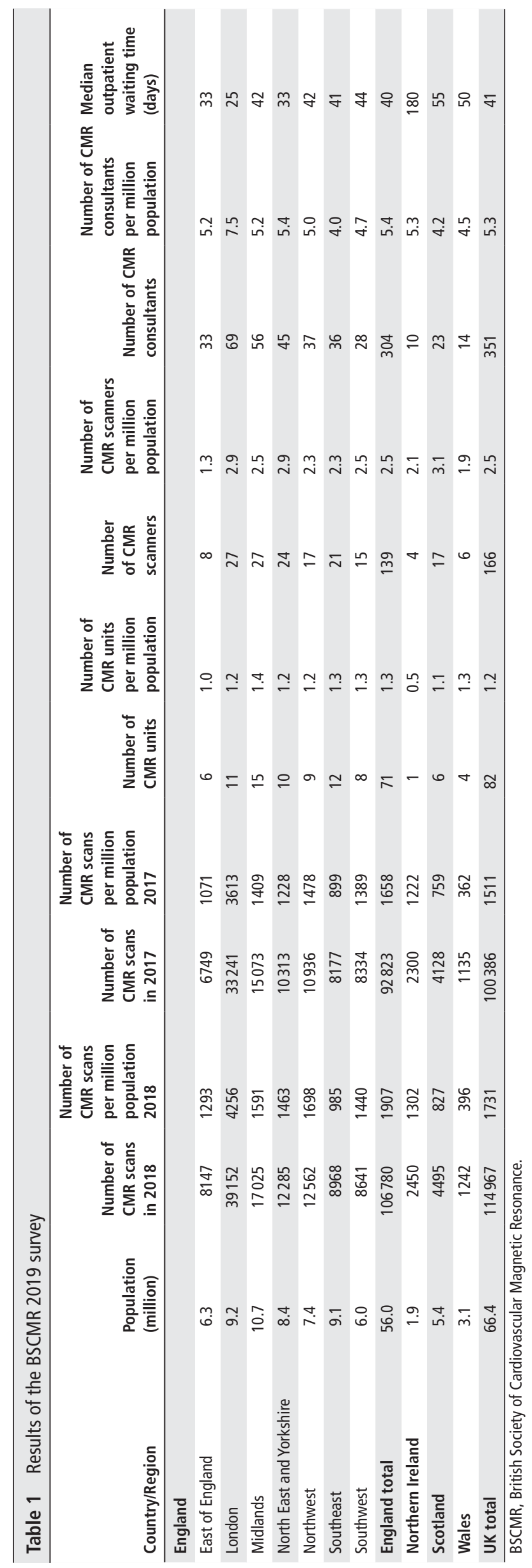




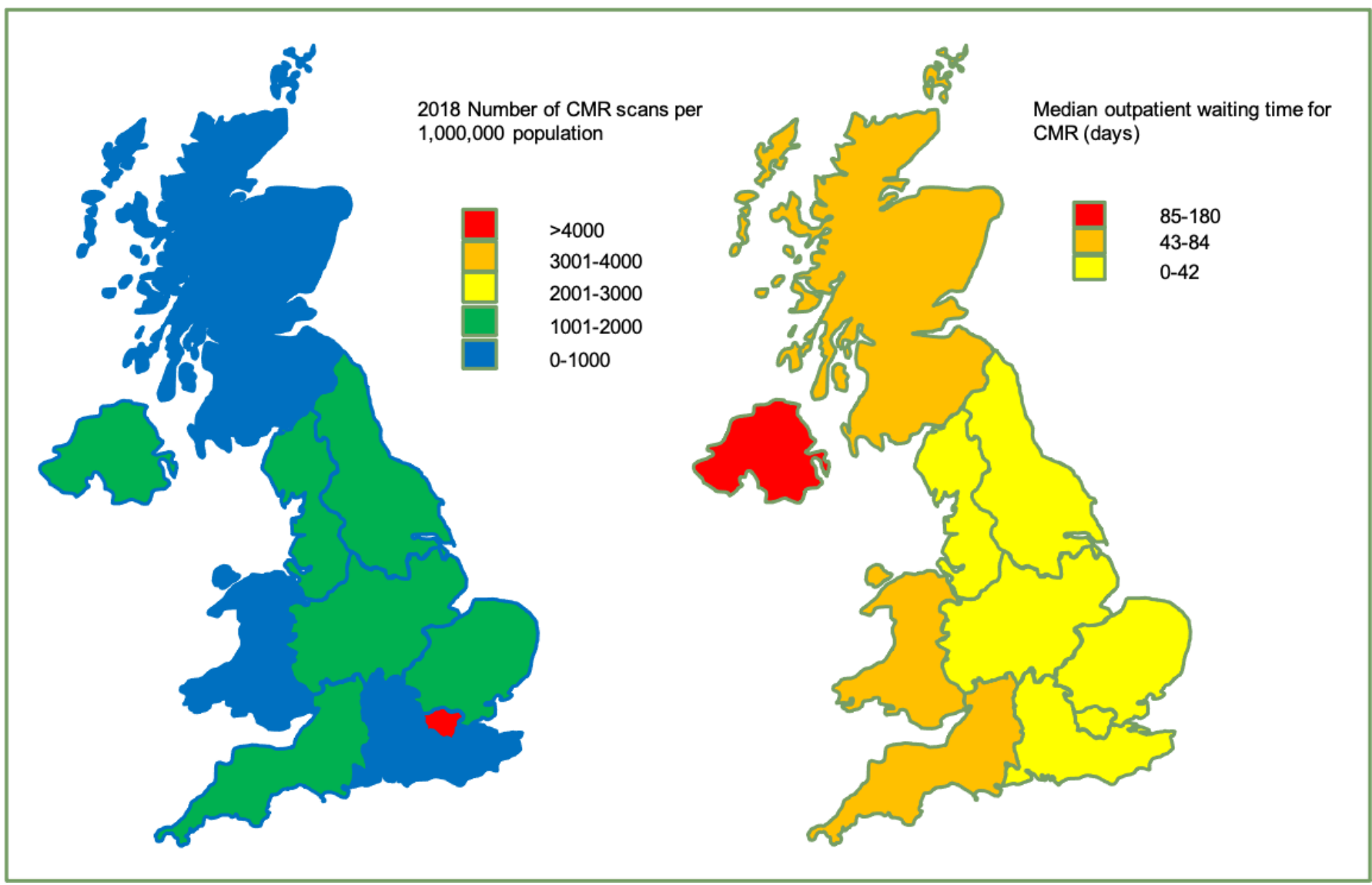

Figure 1 (A) Map showing number of cardiovascular magnetic resonance (CMR) scans per million population by UK region in 2018. (B) Map showing median outpatient waiting time for CMR by UK region (days).

for patients with cardiac implanted electronic devices included 5 tertiary referral centres. Finally, 54 of 73 units (74\%) had access to T1 mapping, 18 of 72 units (25\%) had general anaesthetic (GA) cardiac lists and 3 of 74 units (4\%) had an interventional CMR programme.

\section{DISCUSSION}

The current BSCMR survey is the first to reach a $100 \%$ response rate across the UK. We therefore have a unique and valuable insight into the 'real-world' state of UK CMR service delivery, not currently available in any other government or NHS dataset. The 100\% response rate is itself remarkable and a testament to the engagement of physicians active in CMR in the UK with a representative professional society (BSCMR).

The three iterations of the BSCMR survey have shown a remarkable growth in the use of CMR at approximately fivefold over the last 10 years, although this will to a degree be an overestimate as previous surveys did not achieve a $100 \%$ response rate. There is unfortunately a paucity of datasets from other countries with which to compare our results. There are publicly available data from the US Medicare system, which showed that in 2017

Table 2 Number (\%) of CMR units by scan volume

\begin{tabular}{llcccr}
\hline \multicolumn{5}{c}{ Number of CMR centres and their annual scan volumes/year } \\
\hline Year & No data & $<300$ & $300-500$ & $501-1000$ & $>1000$ \\
2018 & 0 & $7(9 \%)$ & $20(24 \%)$ & $23(28 \%)$ & $32(39 \%)$ \\
2013 & $5(9 \%)$ & $9(16 \%)$ & $14(25 \%)$ & $7(13 \%)$ & $20(36 \%)$ \\
\hline
\end{tabular}

CMR, cardiovascular magnetic resonance. there were 26796 CMR scans performed on Medicare beneficiaries, compared with 102886 scans in the UK. ${ }^{15}$ Although
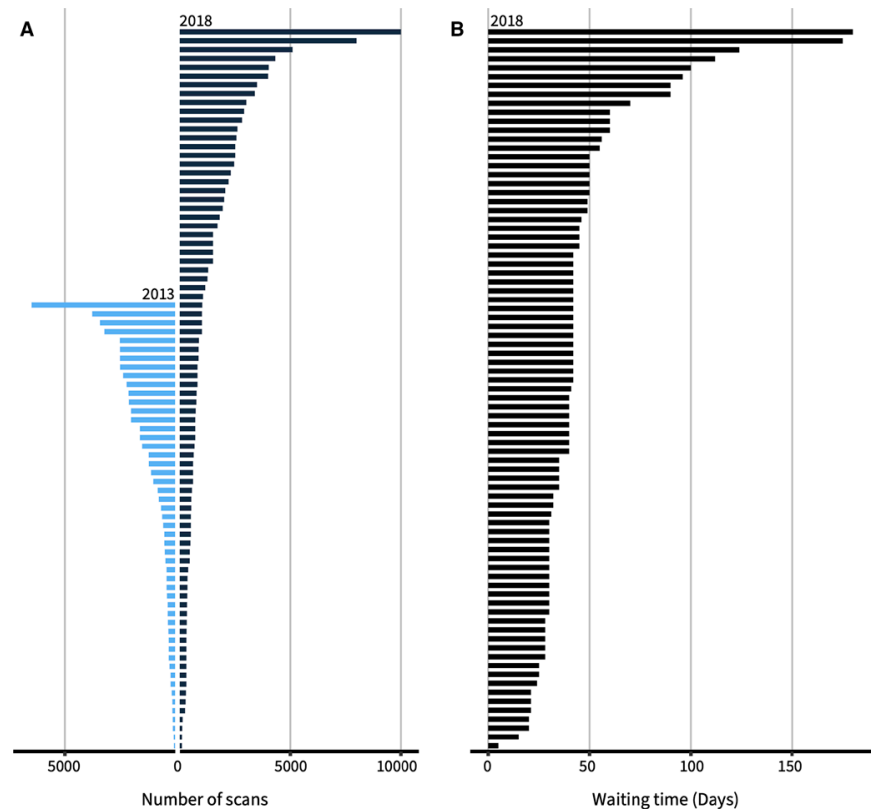

Figure 2 (A) Number of scans by cardiovascular magnetic resonance (CMR) unit in 2018 (black bars). Data for 2013 are shown in blue for comparison. The units are ranked by volume for each year with no linkage between 2013 and 2018 data. (B) Outpatient waiting times for CMR by unit (days). 
Medicare only covers $17.8 \%$ of the population of the USA, beneficiaries are in general aged over 65 years where the burden of cardiovascular disease is greatest. Given that the population of the USA is $329000000,{ }^{16} 17.8 \%$ of the population represents $\sim 58562$ 000, giving a rate of CMR among Medicare beneficiaries of $\sim 406$ scans/million; the comparator for the UK in 2017 was 1511, 3.7 times higher. The EuroCMR registry collected data on 27781 scans from 57 sites in 15 countries between 2007 and $2012^{17}$ and the Society for Cardiovascular Magnetic Resonance has sponsored the Global CMR Registry project which has collected data from 62456 scans between 2013 and 2017 from 10 centres. ${ }^{18}$ While these are both registries looking at indications and clinical outcomes rather than scan volumes, it is clear that viewed internationally, the UK CMR activity levels are numerically large. There are significant benefits to patients from the widespread use of this imaging modality in terms of more sophisticated phenotyping, for example, non-invasive rather than invasive assessment for the aetiology of heart failure is both more clinically effective and also safer. ${ }^{19}$

However, growth has not been uniform across the UK, with wide disparities in use of and access to CMR. The annual CMR volume per unit varies widely from 98 to 10000 patients. The BSCMR previously recommended a minimum number of scans per centre per year of 300 , but some low volume centres may be in their first year of CMR practice. ${ }^{20}$ In terms of CMR activity by million population for the year 2018, this varied from a low of 396 in Wales to a high of 4256 in London, a greater than 10 -fold difference. Data analysis by region may be affected by patients being sent across regional boundaries for CMR, but this also highlights low access to CMR in their home region. However, we should note that CMR services in London include supra-regional and national services such as the National Amyloid Centre, and specialised units for thalassaemia, three centres for paediatric and adult congenital heart disease and a service for non-conditional cardiac devices, and this will lead to apparent higher activity levels in the London region per million population.

In 2010, the BSCMR and British Society of Cardiovascular Imaging estimated CMR activity would need to be $\sim 2275$ scans per million adults per year. ${ }^{20}$ While 10 years later it is likely that the need will have increased, our data show that this target has been achieved in London but not in any other region of the UK. It is interesting to speculate why there is such a variation in activity across the UK. The most likely explanation is that cardiologists with significant experience of CMR are aware of its utility and have a lower threshold for referral than those with more limited exposure. A second possibility is that in some areas long waiting times are a disincentive to refer for CMR. A third possibility is that some areas have very well-established nuclear medicine services and that this is used in preference to CMR for ischaemia and viability assessment, despite the fact that CMR has been shown to have greater diagnostic accuracy, ${ }^{21}{ }^{22}$ prognostic ability $^{23}$ and is more cost-effective from an NHS perspective, ${ }^{2425}$ although the rapid expansion in cardiac CT services has further complicated the picture. However, where CMR activity rates are low, it is likely that patients are being managed without the potential benefits and insights of this advanced cardiac imaging technology, not just in coronary artery disease, but across the full range of CMR indications. ${ }^{2}$ This disparity in access to CMR is one of the main findings of this survey.

Clinical volume is an important measure of access to CMR, but so too are waiting times. This survey shows that the median of the mean reported outpatient waiting times for CMR was 25 days in London and 180 days in Northern

\section{Key messages}

What is already known on this subject?

- Cardiovascular magnetic resonance (CMR) is well-established in the UK with high scan volumes by international standards.

- The British Society for CMR has periodically surveyed all UK CMR units, starting in 2008.

\section{What might this study add?}

- There has been an approximately fivefold increase in CMR use in the UK since 2008.

- The clinical use of CMR is highly variable across the UK with a $>10$-fold difference between the region with the highest and the lowest scan volumes.

- Waiting times are also highly variable across regions with a sixfold difference between the region with the shortest and the longest mean wait.

\section{How might this impact on clinical practice?}

- This regional variation is a concern both for equity of provision of advanced cardiac imaging by CMR, and equity of clinical care across the UK, and should be addressed.

Ireland, a sevenfold difference. Given that this is a mean some patients may be waiting significantly longer. For coronary artery disease or cardiomyopathy, for instance, a 6-month wait may be clinically meaningful if decisions about revascularisation or device implantation are being based on the results of CMR exams, so this variation in waiting time may be a clinical concern.

The limitations of this survey are that the data are selfreported and therefore may not be completely accurate, but a strength is the engagement of all UK CMR centres. Small volume private CMR units may not have been captured by this survey, but private scans performed in NHS units have been. Waiting time data may not reflect planned interval scans. Finally as this is a survey we do not present outcome data.

Overall, our data indicate a lack of equitable access to CMR across the UK. Where there is clear evidence of resource underprovision, action is needed by healthcare providers, the NHS and government, bearing in mind the complex funding arrangements for CMR in the UK. High levels of regional variation in access to CMR are unacceptable given its strong evidence base and the high-level recommendations for its use in international clinical care guidelines.

\section{CONCLUSIONS}

This survey provides a unique, contemporary, 'real-world' insight into a national CMR service delivery model with $100 \%$ centre engagement. The 10-year growth in CMR usage at approximately fivefold has been remarkable but heterogeneous across the UK, with some regions still reporting low usage or long waiting times which may be of clinical concern.

\section{Author affiliations}

${ }^{1}$ Cardiology, West Hertfordshire Hospitals NHS Trust, Watford, UK

${ }^{2}$ MRC London Institute of Medical Sciences, Imperial College London, London, UK

${ }^{3}$ University College London Institute of Cardiovascular Science, London, UK

${ }^{4}$ Centre for Inherited Heart Muscle Conditions, Royal Free Hospital, London, UK

${ }^{5}$ Department of Cardiovascular Sciences, University of Leicester, Leicester, UK

${ }^{6}$ NIHR Leicester Biomedical Research Centre, Glenfield Hospital, Leicester, UK

${ }^{7}$ BHF Glasgow Cardiovascular Research Centre, University of Glasgow, Glasgow, UK 
${ }^{8}$ Cardiology, Golden Jubilee National Hospital, Clydebank, UK

${ }^{9}$ University of Oxford Centre for Clinical Magnetic Resonance Research, Division of Cardiovascular Medicine, Radcliffe Department of Medicine, University of Oxford, Oxford, UK

${ }^{10}$ Cardiology, Liverpool Heart and Chest Hospital NHS Trust, Liverpool, Merseyside, UK

${ }^{11}$ Adult Congenital Heart Disease Unit, University Hospitals Birmingham, Birmingham, UK

${ }^{12}$ Cardiology, Barts Heart Centre, London, UK

${ }^{13}$ Leeds Institute of Cardiovascular and Metabolic Medicine, University of Leeds,

Leeds, UK

${ }^{14}$ Cardiology, Leeds Teaching Hospitals NHS Trust, Leeds, UK

Twitter Niall G Keenan @drniallkeenan, Gabriella Captur @gabycaptur, Timothy Fairbairn@fairbairn_tim and Declan P O'Regan @DrDeclanORegan

Acknowledgements The authors would like to thank all CMR units and colleagues who completed the survey.

Contributors All authors meet all four criteria below: substantial contributions to the conception and design of the work, and the acquisition, analysis and interpretation of data. Drafting the work or revising it critically for important intellectual content. Final approval of the version published. Agreement to be accountable for all aspects of the work in ensuring that questions related to the accuracy or integrity of any part of the work are appropriately investigated and resolved. NGK and JPG are responsible for the overall content as guarantors.

Funding The authors have not declared a specific grant for this research from any funding agency in the public, commercial or not-for-profit sectors.

Competing interests None declared.

Patient and public involvement Patients and/or the public were not involved in the design, or conduct, or reporting, or dissemination plans of this research.

Patient consent for publication Not required.

Ethics approval As this was a survey with no patient-level data or intervention, institutional ethical review or board approval was not required.

Provenance and peer review Not commissioned; externally peer reviewed.

Data availability statement All data relevant to the study are included in the article or uploaded as supplemental information.

Open access This is an open access article distributed in accordance with the Creative Commons Attribution Non Commercial (CC BY-NC 4.0) license, which permits others to distribute, remix, adapt, build upon this work non-commercially, and license their derivative works on different terms, provided the original work is properly cited, appropriate credit is given, any changes made indicated, and the use is non-commercial. See: http://creativecommons.org/licenses/by-nc/4.0/.

\section{ORCID iDs}

Niall G Keenan http://orcid.org/0000-0002-0841-6989

Gabriella Captur http://orcid.org/0000-0002-5662-0642

Colin Berry http://orcid.org/0000-0002-4547-8636

Saul G Myerson http://orcid.org/0000-0001-5927-0230

Declan P O'Regan http://orcid.org/0000-0002-0691-0270

John P Greenwood http://orcid.org/0000-0002-2861-0914

\section{REFERENCES}

1 Keenan NG, Pennell DJ. CMR of ventricular function. Echocardiography 2007:24:185-93.

2 American College of Cardiology Foundation Task Force on Expert Consensus Documents, Hundley WG, Bluemke DA, et al. ACCF/ACR/AHA/NASCI/SCMR 2010 expert consensus document on cardiovascular magnetic resonance: a report of the American College of cardiology Foundation Task force on expert consensus documents. J Am Coll Cardiol 2010;55:2614-62.

3 Sachdeva R, Valente AM, Armstrong AK, et al. ACC/AHA/ASE/HRS/ISACHD/SCAI/SCCT/ SCMR/SOPE 2020 Appropriate Use Criteria for Multimodality Imaging During the Follow-Up Care of Patients With Congenital Heart Disease: A Report of the American College of Cardiology Solution Set Oversight Committee and Appropriate Use Criteria Task Force, American Heart Association, American Society of Echocardiography, Heart Rhythm Society, International Society for Adult Congenital Heart Disease, Society for Cardiovascular Angiography and Interventions, Society of Cardiovascular Computed Tomography, Society for Cardiovascular Magnetic Resonance, and Society of Pediatric Echocardiography. J Am Coll Cardiol 2020;75:657-703.

4 Wolk MJ, Bailey SR, Doherty JU, et al. ACCF/AHA/ASE/ASNC/HFSA/HRS/SCAI/SCCT/SCMR/ STS 2013 multimodality appropriate use criteria for the detection and risk assessment of stable ischemic heart disease: a report of the American College of cardiology Foundation appropriate use criteria Task force, American heart association, American Society of echocardiography, American Society of nuclear cardiology, heart failure Society of America, heart rhythm Society, Society for cardiovascular angiography and interventions, society of cardiovascular computed tomography, Society for cardiovascular magnetic resonance, and society of thoracic surgeons. J Am Coll Cardiol 2014:63:380-406.

5 Doherty JU, Kort S, Mehran R, et al. ACC/AATS/AHA/ASE/ASNC/HRS/SCAI/SCCT/ SCMR/STS 2019 Appropriate Use Criteria for Multimodality Imaging in the Assessment of Cardiac Structure and Function in Nonvalvular Heart Disease: A Report of the American College of Cardiology Appropriate Use Criteria Task Force, American Association for Thoracic Surgery, American Heart Association, American Society of Echocardiography, American Society of Nuclear Cardiology, Heart Rhythm Society, Society for Cardiovascular Angiography and Interventions, Society of Cardiovascular Computed Tomography, Society for Cardiovascular Magnetic Resonance, and the Society of Thoracic Surgeons. J Am Coll Cardiol 2019;73:488-516.

6 Doherty JU, Kort S, Mehran R, et al. ACC/AATS/AHA/ASE/ASNC/HRS/SCAI/SCCT/ SCMR/STS 2017 Appropriate Use Criteria for Multimodality Imaging in Valvular Heart Disease: A Report of the American College of Cardiology Appropriate Use Criteria Task Force, American Association for Thoracic Surgery, American Heart Association, American Society of Echocardiography, American Society of Nuclear Cardiology, Heart Rhythm Society, Society for Cardiovascular Angiography and Interventions, Society of Cardiovascular Computed Tomography, Society for Cardiovascular Magnetic Resonance, and Society of Thoracic Surgeons. J Am Coll Cardiol 2017;70:1647-72.

7 Knuuti J, Wijns W, Saraste A, et al. 2019 ESC guidelines for the diagnosis and management of chronic coronary syndromes. Eur Heart J 2020;41:407-77.

8 Ponikowski P, Voors AA, Anker SD, et al. 2016 ESC guidelines for the diagnosis and treatment of acute and chronic heart failure: The Task Force for the diagnosis and treatment of acute and chronic heart failure of the European Society of Cardiology (ESC) developed with the special contribution of the Heart Failure Association (HFA) of the ESC. Eur Heart I 2016:37:2129-200.

9 Antony R, Daghem M, McCann GP, et al. Cardiovascular magnetic resonance activity in the United Kingdom: a survey on behalf of the British Society of cardiovascular magnetic resonance. J Cardiovasc Magn Reson 2011;13:57.

10 Ripley DP, Sado DM, McCann GP, et al. 26 Cardiovascular magnetic resonance activity in the united kingdom: results of the 2014 bscmr survey. Heart 2015;101:A14.3-15.

11 Dreisbach JG, Nicol ED, Roobottom CA, et al. Challenges in delivering computed tomography coronary angiography as the first-line test for stable chest pain. Heart 2018; 104:921-7.

12 Asher A, Ghelani R, Thornton G, et al. UK perspective on the changing landscape of non-invasive cardiac testing. Open Heart 2019;6:e01186.

13 Office for National Statistics. Available: http://www.ons.gov.uk/ [Accessed 1 Jun 20].

14 NHS England. Available: https://www.england.nhs.uk/integratedcare/stps/view-stps/ [Accessed 1 Jun 20].

15 Medicare provider utilization and payment data: physician and other supplier. Available: https://data.cms.gov/Medicare-Physician-Supplier/Medicare-ProviderUtilization-and-Payment-Data-Phy/fs4p-t5eq [Accessed 1 Jun 20].

16 United States Census Bureau. Available: https://www.census.gov/popclock/ [Accessed 1 Apr 2020].

17 Bruder O, Wagner A, Lombardi M, et al. European Cardiovascular Magnetic Resonance (EuroCMR) registry--multi national results from 57 centers in 15 countries. J Cardiovasc Magn Reson 2013;15:9.

18 Global Cardiovascular Magnetic Resonance Registry (GCMR) Investigators, Kwong RY, Petersen $\mathrm{SE}$, et al. The global cardiovascular magnetic resonance registry (GCMR) of the Society for cardiovascular magnetic resonance (SCMR): its goals, rationale, data infrastructure, and current developments. J Cardiovasc Magn Reson 2017;19:23.

19 Assomull RG, Shakespeare C, Kalra PR, et al. Role of cardiovascular magnetic resonance as a gatekeeper to invasive coronary angiography in patients presenting with heart failure of unknown etiology. Circulation 2011:124:1351-60.

20 Delivering Cardiovascular Magnetic Resonance in the UK. BSCMR/BSCI guidelines. Version 1.0, 2010. Available: https://www.bscmr.org/wp-content/uploads/2013/09/ BSCMRBSCI_CMR_standards_2010.doc

21 Greenwood JP, Maredia N, Radjenovic A, et al. Clinical evaluation of magnetic resonance imaging in coronary heart disease: the CE-MARC study. Trials 2009;10:62.

22 Greenwood JP, Maredia N, Younger JF, et al. Cardiovascular magnetic resonance and single-photon emission computed tomography for diagnosis of coronary heart disease (CE-MARC): a prospective trial. Lancet 2012;379:453-60.

23 Greenwood JP, Herzog BA, Brown JM, et al. Prognostic value of cardiovascular magnetic resonance and single-photon emission computed tomography in suspected coronary heart disease: long-term follow-up of a prospective, diagnostic accuracy cohort study. Ann Intern Med 2016;165:1-9.

24 Walker S, Girardin F, McKenna C, et al. Cost-Effectiveness of cardiovascular magnetic resonance in the diagnosis of coronary heart disease: an economic evaluation using data from the CE-MARC study. Heart 2013;99:873-81.

25 Walker S, Cox E, Rothwell B, et al. Cost-effectiveness of cardiovascular imaging for stable coronary heart disease. Heart 2021;107:381-8. 